\title{
Behavior of CFRP Plate in Simulated ICCP System of Concrete Structures
}

\author{
Ji-Hua Zhu, Miaochang Zhu, Ningxu Han, Feng Xing, and Wei Liu \\ Shenzhen Key Lab on Durability of Civil Engineering, College of Civil Engineering, Shenzhen University \\ Luca Bertolini \\ Department of Chemistry, Materials and Chemical Engineering, Politecnico di Milano
}

\begin{abstract}
An innovative effort was made to utilize carbon fiber reinforced polymer (CFRP) plate as an anode in impressed current cathodic protection (ICCP) of reinforced concrete structure. The feasibility was explored by bonding CFRP strips to concrete and then applying protection current through CFRP strips to steel rebar in concrete. Service life and performance of CFRP plate were investigated in simulated ICCP systems with various configurations. Steel potential results confirmed that the steel rebar in concrete maintained at a satisfactory level with the applied protection current. It is shown that CFRP strips can be successfully used in various solutions as an anode material.
\end{abstract}

\section{INTRODUCTION}

Reinforced concrete structures may suffer from premature failure induced by corrosion of the reinforcing steel embedded in the concrete, which implies that a huge investment in strengthening, repair, and rehabilitation is needed to reach their target service lives (ACl 220R-01, 2001). It is well known that chloride ingress is one of the major causes of steel corrosion that in turn leads to concrete cracking due to the expansion exerted by corrosion products (Bertolini, 2008; Zhao et al., 2011; Zhao, Hu, Yu, \& Jin, 2011). The chloride transport mechanism has been reported by Tang $(1999 \mathrm{a}, 1999 \mathrm{~b})$ and Li and Page (2000). The corrosion of steel in concrete is generally understood as an electrochemical phenomenon (Cigna et al., 2003). Nowadays various welldeveloped methods are available for controlling the steel corrosion in concrete (Chung, 2000). One of the most effective methods, impressed current cathodic protection (ICCP; Bertolini, Bolzoni, Pedeferri, Lazzari, \& Pastore, 1998; Pedeferri, 1996) can usually afford sufficient protection and in some cases has even been regarded as the only way to control steel corrosion (Arnhart, 1982). In an ICCP system, a cathodic current is applied to the reinforcing steel, resulting in shifting of the steel potential towards a level at which the corrosion rate is negligible (Bertolini et al., 1998; Pedeferri, 1996).

It is of crucial importance to select a proper anode for the delivery of the protection current from the surface through the concrete to the steel rebar. Many researches have been carried out using different types of anodes, including thermal sprayed zinc anodes (Bullard, Covino, Cramer, \& McGill, 1996), thermal sprayed titanium anodes (Brousseau et al., 1998; Cramer et al., 1999), titanium mesh (Gerardo \& Donald, 2000), and conductive paint or overlay coating anodes (Bertolini, Bolzoni, Pastore, \& Pedeferri, 2004; Gerardo \& Donald, 1997; Orlikowski, Cebulski, \& Darowicki, 2004). However, a large-scale application of these anodes has been hindered due to a number of serious drawbacks, such as bond deficiency, installation inconvenience, anode-concrete interface degradation, and high cost.

Carbon fiber reinforced polymer (CFRP) consists of extremely strong and light carbon fibers embedded in a polymer matrix. CFRP is extensively used as a structural strengthening material due to its sound mechanical properties, good durability, and other considerations such as esthetics and ease of installation. Researches on applications of CFRP in structures were summarized by international specifications (ACl 562M-13, 2013; BS EN 1504$4,2004)$. It should be noted that CFRP may also be a potential anode material in ICCP systems, due to its good electrical conductivity and electrochemical properties. For instance, it was shown that CFRP plates embedded in concrete may produce galvanic effects when coupled with steel bars (Bertolini, Gastaldi, \& Pedeferri, 2007).

Recently, an effort was made to utilize CFRP as an anode in an ICCP system. Reinforced concrete cylinders and beams were placed into an accelerated corrosion environment, and they were protected by means of ICCP, where CFRP sheet was considered as the anode (Gadve, Mukherjee, \& Malhotra, 2010a, 2010b). CFRP sheet was bonded to the concrete surface with epoxy resin whose electrical conductivity 
was improved by the addition of graphite particles. It was shown that the system could provide sufficient protection against the steel corrosion in concrete. However, the mechanism underlying the role played by the CFRP sheet is unclear, as no electrochemical reaction accompanied by charge transfer was found to have occurred on the CFRP sheet. Additionally, the long-term performance of CFRP as an anode with anodic polarization should be studied to figure out the suitability for the application of this type of ICCP system in practice.

The goals of the present research work are to study the feasibility of using CFRP plate as an anode in ICCP of concrete and to investigate the influence of different solutions and current densities on the electrical and mechanical properties of CFRP plate by means of simulated ICCP systems.

\section{FEASIBILITY OF CFRP PLATE AS AN ANODE}

An integral ICCP system was set up using a CFRP plate as the impressed current anode, as shown in Figure 1. This system consisted of an anode (CFRP), a cathode (steel rebar in concrete), the electrolyte (concrete), a power source, and a copper/copper sulfate reference electrode (CSE). The length, width, and height of the concrete block were $300 \mathrm{~mm} \times 150 \mathrm{~mm} \times 150 \mathrm{~mm}$, respectively. The water/cement ratio of the concrete mix was 0.45 . A ribbed steel rebar of $16 \mathrm{~mm}$ in diameter was placed centrally in the concrete block. The length of the steel rebar embedded in the concrete was $120 \mathrm{~mm}$; a hole of $2 \mathrm{~mm}$ in diameter was drilled at one end of the steel rebar for electrical connection. Both ends of the steel rebar were coated with epoxy resin. Sodium chloride was added to the concrete mix to facilitate corrosion of the steel reinforcement. The amount of sodium chloride was $0.5 \%$ by mass of cement.

The CSE reference electrode was installed near the rebar during fabrication of the concrete block. The steel potential $(E)$ was measured regularly with a multimeter of $10 \mathrm{M} \Omega$ impedance for a general evaluation of the corrosion status of the steel rebar. According to the ASTM Standard (ASTM C876-09, 2009), a potential more negative than $-350 \mathrm{mV}$ vs. CSE indicates a $90 \%$ probability of steel corrosion. Therefore, when $E$ was measured to be more negative than $-350 \mathrm{mV}$ vs. CSE, ICCP was immediately applied to the steel by connecting the steel rebar to the negative terminal of the power source, and CFRP strips to the positive terminal, as shown in Figure 1. The CFRP strips were bonded to the concrete surface using cement paste with the same water/cement ratio as the concrete. Before

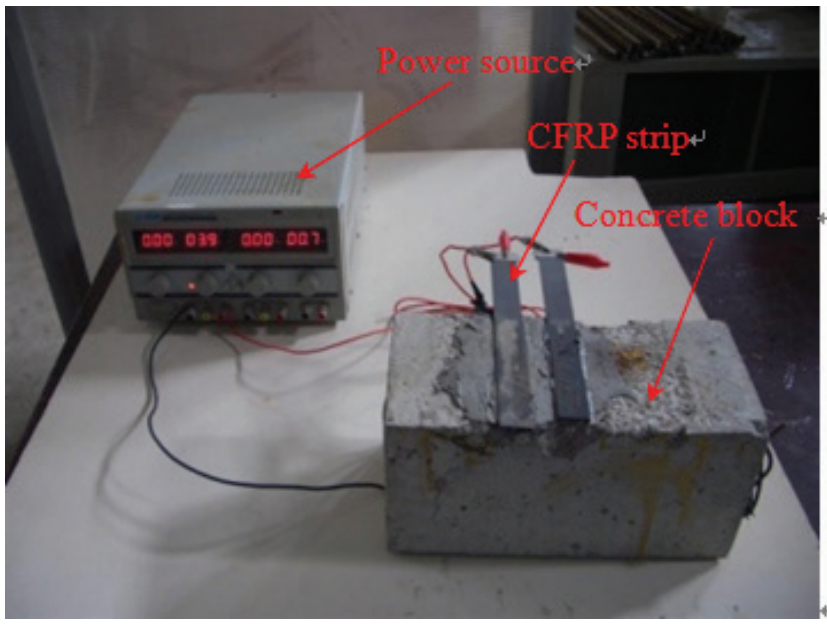

Figure 1. Impressed current cathodic protection system with CFRP anode.

bonding CFRP strips to the concrete, the CFRP strips were sand blasted to remove superficial electrically nonconductive organics and to expose electrically conductive parts. A feeding voltage of $4.0 \mathrm{~V}$ was applied and maintained during the test.

Figure 2 shows the measured "instant off" potential $\left(E_{\text {off }}\right)$ of steel before and during the application of ICCP. $E_{\text {off }}$ was around $-800 \mathrm{mV}$ vs. CSE when the protection current was applied and was stably maintained at practically the same level over the 5-week duration of the test. It is recommended that steel corrosion could be effectively impeded by shifting the steel potential toward a level less than $-550 \mathrm{mV}$ against saturated $\mathrm{Ag} / \mathrm{AgCl}$ or $-668 \mathrm{mV}$ against CSE (Takewaka, 1993). Thus, the steel rebar in concrete was confirmed to be protected by the application of ICCP, according to this criterion. It can be concluded that the CFRP strips are capable of serving as an impressed current anode by supplying the required current to the steel rebar to be protected.

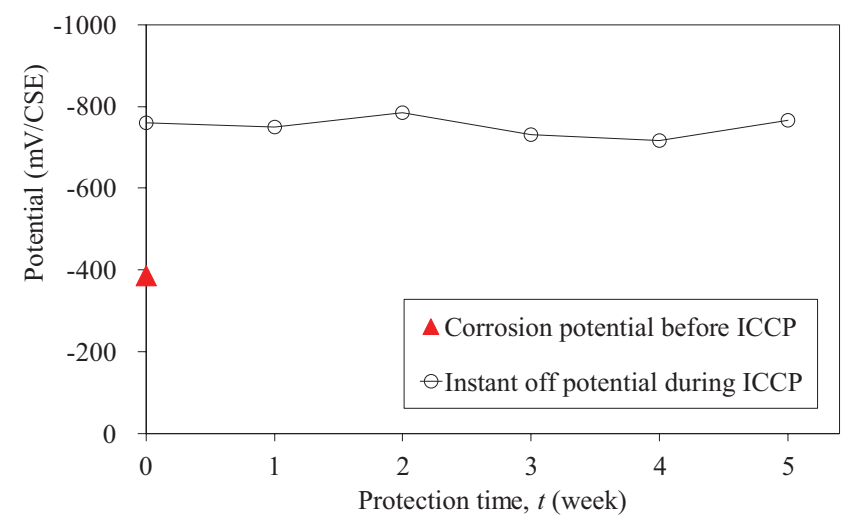

Figure 2. Measured steel potential against copper/copper sulfate electrode (CSE) before and during the application of ICCP. 


\section{BEHAVIOR OF CFRP PLATE IN SIMULATED ICCP SYSTEMS}

\subsection{Specimen preparation}

CFRP plate with $0 / 90$ orthotropic arrangement of carbon fibers was used in the test. The CFRP plates were cut into strips with the same geometries and dimensions, as shown in Figure 3. All strips were sand blasted to remove superficial electrically nonconductive organics and to expose conductive parts of the CFRP strips. Afterwards, all strips were coated with epoxy resin except for the testing area at middle length. The testing area of each specimen was a rectangle of $100 \mathrm{~mm}$ in length and $25 \mathrm{~mm}$ in width, located in the center of a single side of the specimen, as shown in Figure 3.

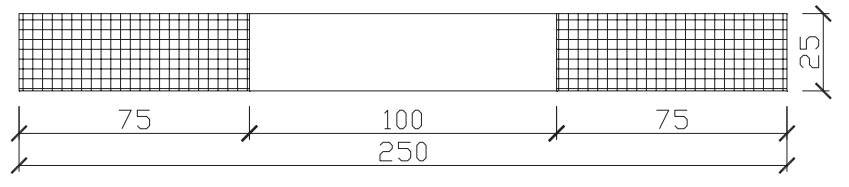

Figure 3. Geometric information for CFRP strips.

\subsection{Galvanic tests}

For the sake of simplicity, CFRP plate was employed as an anode in simulated ICCP systems with different solutions, as shown in Figure 4. Anodic polarization was obtained by connecting CFRP strips (anode) and stainless steel strips (cathode) to the positive and negative terminals of a constant direct current source, respectively. A total of 15 CFRP strips were used to investigate the effect of anodic polarization on CFRP plate in various solutions, as described in Table 1. Different types of solutions and magnitudes of current density were investigated. Three kinds of solutions, namely $3.5 \% \mathrm{NaCl}$ solution (by mass percentage of solution), a mixture of saturated limewater with $1 \% \mathrm{NaCl}$ (by mass percentage of solution), and saturated limewater, were used as electrolytes in the simulated ICCP systems. The purpose of using different solutions was to investigate the CFRP plate's resistance to chlorine and oxygen evolution in the different environments. According to the Faraday's law, electrochemical reactions are strongly dependent on charge quantity. Thus various current densities of $0.2,2,20$, and $40 \mathrm{~A} / \mathrm{m}^{2}$ were maintained during galvanizing. The voltage between the CFRP and stainless steel strips was measured in every $12 \mathrm{~h}$ for each specimen. In addition, the $\mathrm{pH}$ of the solutions was regularly monitored using $\mathrm{pH}$ test strips with an accuracy of 0.5 . It should be noted that no stirring and vibration were performed so as to approximate the real working conditions of an anode as closely as possible. The galvanizing period was 25 days.

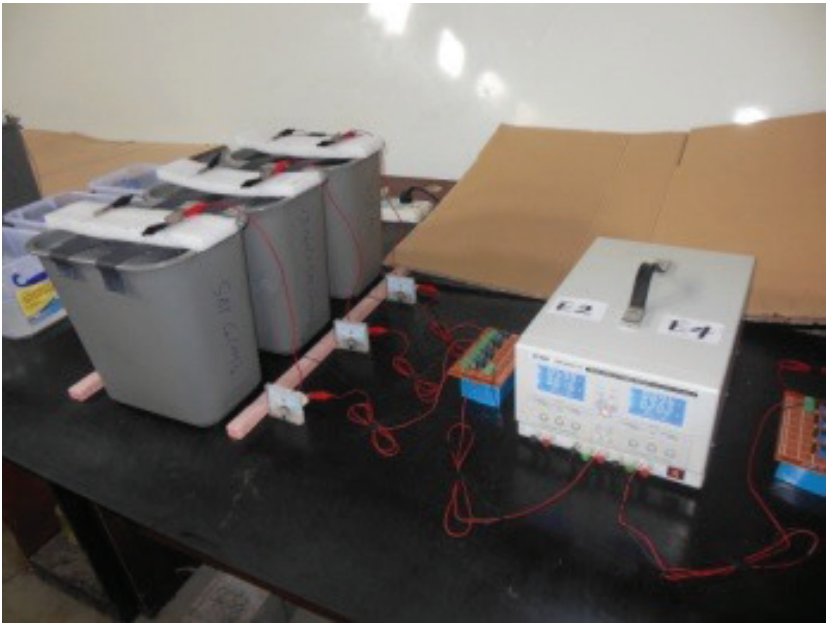

Figure 4. Test setup of simulated ICCP systems.

Table 1. Specimens of series under different anodic polarization conditions.

\begin{tabular}{|c|c|c|c|c|}
\hline Series & Specimen & $\begin{array}{c}\text { Current } \\
\text { (mA) }\end{array}$ & $\begin{array}{c}\text { Current } \\
\text { Density }\left(A / m^{2}\right)\end{array}$ & Solution \\
\hline \multirow[t]{3}{*}{ RF } & $\mathrm{RF}-\mathrm{NaCl}$ & - & - & $\mathrm{NaCl}$ \\
\hline & RF-Mix & - & - & Mix \\
\hline & $\mathrm{RF}-\mathrm{Ca}(\mathrm{OH})_{2}$ & - & - & $\mathrm{Ca}(\mathrm{OH})_{2}$ \\
\hline \multirow[t]{3}{*}{10.5} & $10.5-\mathrm{NaCl}$ & 0.5 & 0.2 & $\mathrm{NaCl}$ \\
\hline & I0.5-Mix & 0.5 & 0.2 & Mix \\
\hline & $\mathrm{I0.5}-\mathrm{Ca}(\mathrm{OH})_{2}$ & 0.5 & 0.2 & $\mathrm{Ca}(\mathrm{OH})_{2}$ \\
\hline \multirow[t]{3}{*}{15} & I5-NaCl & 5 & 2.0 & $\mathrm{NaCl}$ \\
\hline & I5-Mix & 5 & 2.0 & Mix \\
\hline & $15-\mathrm{Ca}(\mathrm{OH})_{2}$ & 5 & 2.0 & $\mathrm{Ca}(\mathrm{OH})_{2}$ \\
\hline \multirow[t]{3}{*}{150} & $\mid 50-\mathrm{NaCl}$ & 50 & 20.0 & $\mathrm{NaCl}$ \\
\hline & I50-Mix & 50 & 20.0 & Mix \\
\hline & $150-\mathrm{Ca}(\mathrm{OH})_{2}$ & 50 & 20.0 & $\mathrm{Ca}(\mathrm{OH})_{2}$ \\
\hline \multirow[t]{3}{*}{1100} & $\mid 100-\mathrm{NaCl}$ & 100 & 40.0 & $\mathrm{NaCl}$ \\
\hline & I100-Mix & 100 & 40.0 & Mix \\
\hline & $\mathrm{I} 100-\mathrm{Ca}(\mathrm{OH})_{2}$ & 100 & 40.0 & $\mathrm{Ca}(\mathrm{OH})_{2}$ \\
\hline
\end{tabular}

\subsection{Tensile test}

Uniaxial tensile tests were carried out after the completion of the galvanic tests. The intention of carrying out the tensile test was to evaluate the effects of anodic polarization on the mechanical properties of CFRP plate. The CFRP strips were cut to be a dumbbell shape according to the ASTM Standard (ASTM D638-10, 2010) to be sure that the tensile failure takes place in the targeted area. Strain gages were attached in the middle of each specimen. The uniaxial tensile test was carried out with a universal test machine, where both ends of the CFRP strip were tightly gripped, as shown in Figure 5. A tensile loading rate of $0.2 \mathrm{~mm} / \mathrm{min}$ was applied. The tensile force and strain of the CFRP strips were continuously monitored and recorded. 


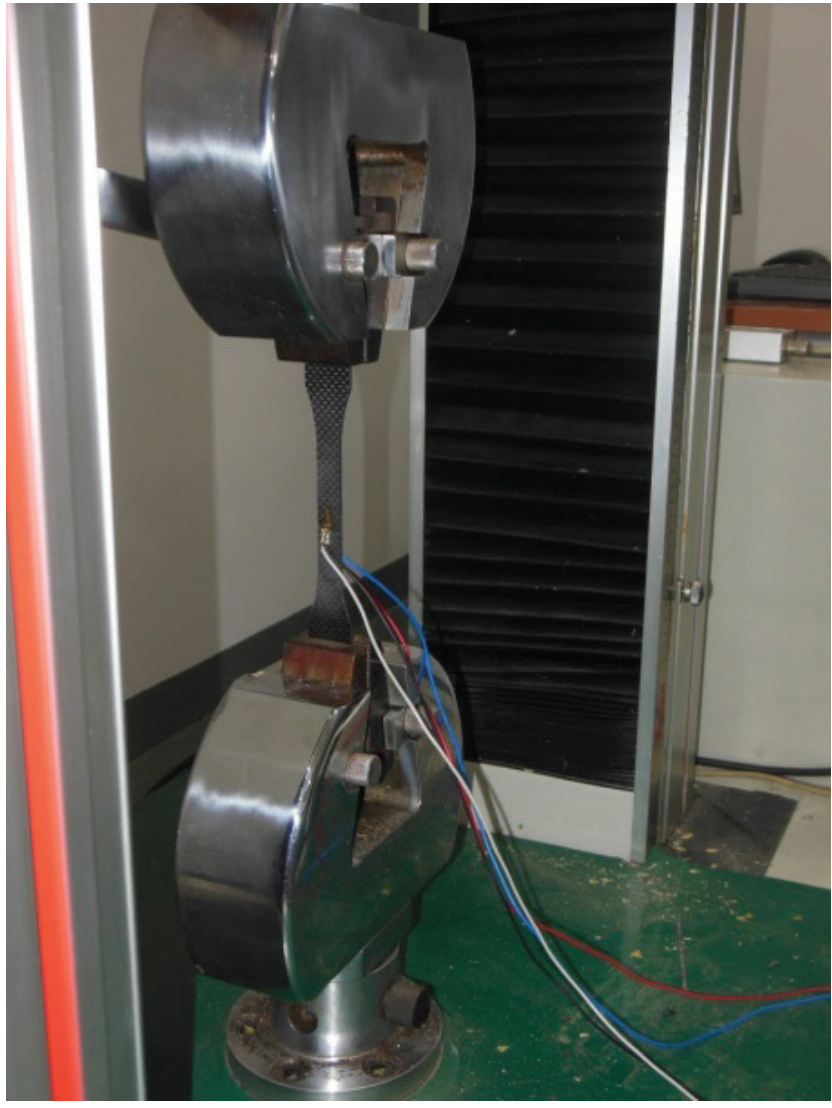

Figure 5. Test rig for tensile tests.

\section{TEST RESULTS}

\subsection{Experimental observations}

Significant changes of surface conditions were observed in CFRP strips of different series. Some white and black sediment appeared on the CFRP strips in the saturated limewater and Mix solution, while no sediment was observed for strips in $3.5 \% \mathrm{NaCl}$ solution. The amount of sediment increased with the applied current. Figure 6 shows surface conditions of CFRP strips subjected to a current density of $40 \mathrm{~A} / \mathrm{m}^{2}$ after $84 \mathrm{~h}$ of anodic polarization in three different solutions. The black sediment may be attributed to electrochemical oxidation (Bismarck et al., 1999a, 1999b; Fukunaga \& Ueda, 2000). The other obvious change was the thickness of the CFRP strips. The thickness increased to $100-150 \%$ of the original value for strips subjected to current densities of 20 and $40 \mathrm{~A} / \mathrm{m}^{2}$ in all three kinds of solutions. Significant swelling of CFRP plate was also found right at the border between the test area and the epoxy resin area for all specimens. No significant change of $\mathrm{pH}$ of the testing solution was observed during the galvanization process.

\subsection{Electrical performance}

For simplicity, the electrical performance was studied on the whole simulated ICCP systems by measuring

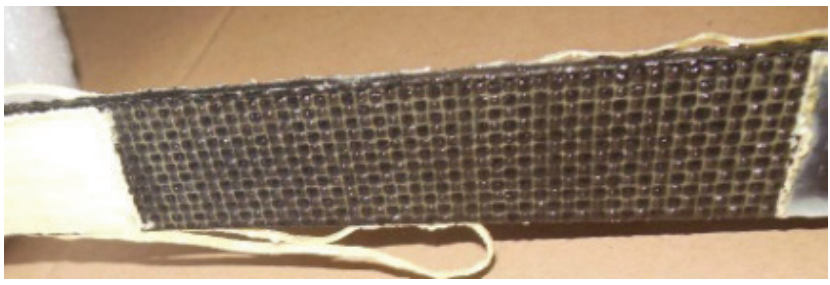

(a) $1100-\mathrm{NaCl}$

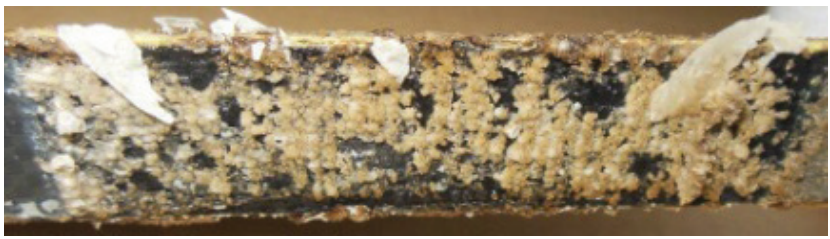

(b) I100-Mix

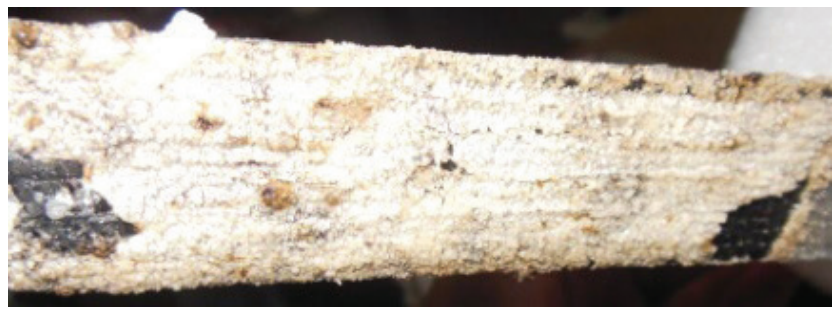

(c) $I 100-\mathrm{Ca}(\mathrm{OH}) 2$

Figure 6. Surface conditions of Series 1100 after $84 \mathrm{~h}$ of anodic polarization in (a) $3.5 \% \mathrm{NaCl}$ solution, (b) a mixture of saturated limewater with $1 \% \mathrm{NaCl}$, and (c) saturated limewater.

the feeding voltage between CFRP (anode) and stainless steel strips (cathode). Figure 7 plots the feeding voltage $(U)$ versus time $(t)$ for specimens. It is evident that $U$ increased slightly with increasing applied current density. The measured voltage was the lowest for the $3.5 \% \mathrm{NaCl}$ solution, followed by the Mix solution, and was the highest for the saturated limewater, as shown in Figure 7. Stable feeding voltages were observed for most of the tests, except for specimens $150-\mathrm{Ca}(\mathrm{OH})_{2}$ and $1100-\mathrm{Ca}(\mathrm{OH})_{2}$. For these two specimens, $U$ increased continuously with time, as shown in Figure 7(c) and (d). The galvanization was stopped when $U$ reached around $40 \mathrm{~V}$ due to the limitation of the power source capacity. The increased voltage was caused by an accumulation of sediment on the surface of the CFRP strips, which could restrict the availability of reactant. Consequently, larger resistance appeared during galvanization.

These selected current densities were too high for CFRP to be used in real reinforced concrete structures. In fact, it was known that the limit to the applied current may be related to concrete acidification. Hence, further research in concrete is required.

\subsection{Mechanic properties}

Uniaxial tensile tests were carried out after completion of the galvanization tests, except for specimens of 


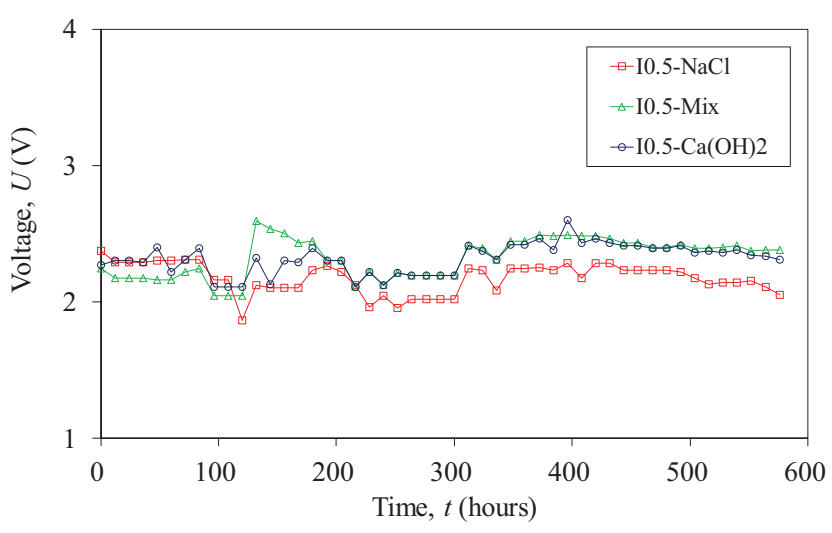

(a) Series 10.5

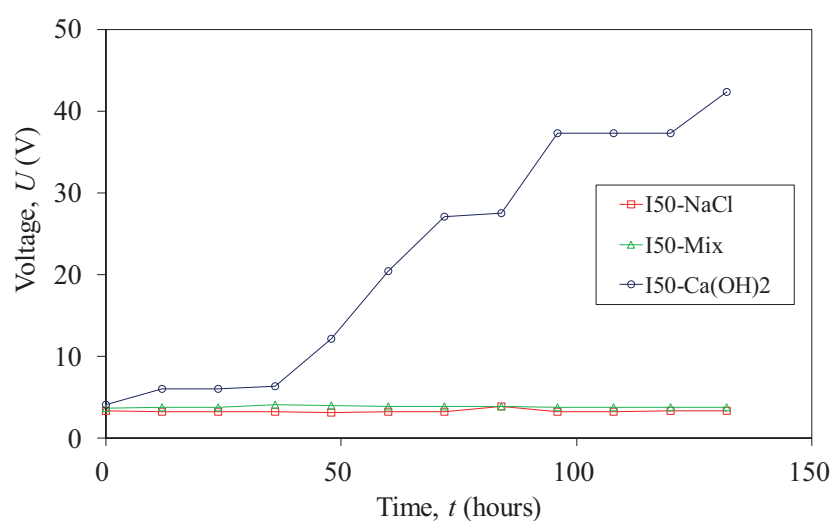

(c) Series 15

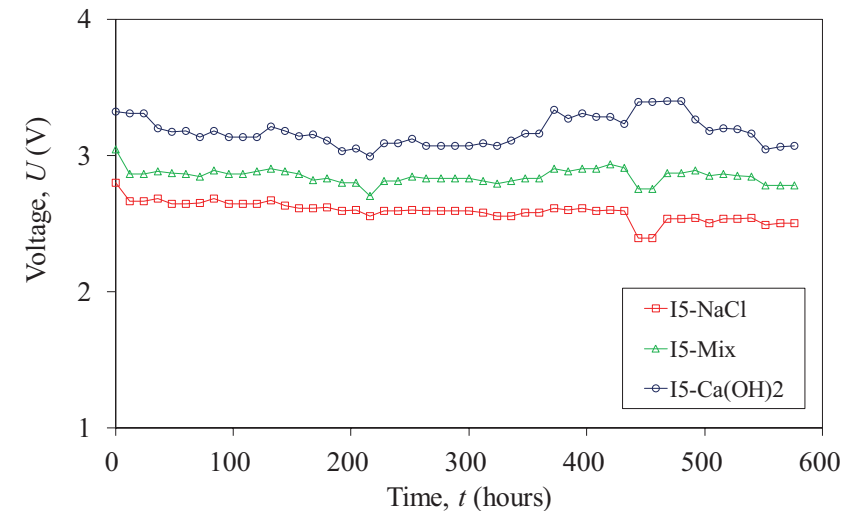

(b) Series 150

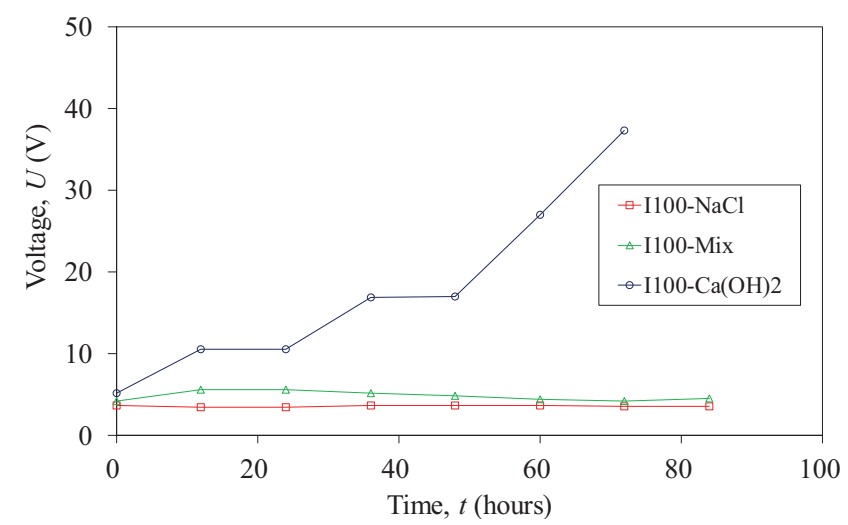

(d) Series 1100

Figure 7. Measured feeding voltage for CFRP strips of different series.

Series 150 and 1100, since their excessive anodic polarization-induced swelling could nullify the mechanical properties. Almost all strips were found to have an identical tensile behavior, that is, stress is proportional to the strain for each CFRP strip. Further information on CFP strips' mechanical properties could be referred to Zhu, al Zhu, Han, Xing, and Liu (submitted for publication).

\section{CONCLUSIONS}

The behavior of CFRP plate as an anode in the ICCP system for reinforced concrete structures was investigated. A comprehensive experimental program was carried out to study electrical and mechanical behavior of CFRP plate in different environments including simulated ICCP systems with varied solutions. The following conclusions can be drawn based on the current research:

(1) Measured potential of the steel rebar in concrete indicated that it is feasible by using CFRP plate as an anode in the ICCP for a reinforced concrete structure.

(2) Tests were also carried out in simulated ICCP systems with various solutions. No significant degradation of both electrical and mechanical performances was found for CFRP strips operated up to very high current densities of $2 \mathrm{~A} / \mathrm{m}^{2}$.

\section{REFERENCES}

ACl 220R-01. (2001). Protection of metals in concrete against corrosion. Ml: American Concrete Institute.

ACI 562M-13. (2013). Code requirements for evaluation, repair and rehabilitation of concrete buildings and commentary. MI: American Concrete Institute.

Arnhart, R. A. (1982). FHWA position on cathodic protection systems, memorandum of FHWA. In: FHWA, ed. Washington, DC.

ASTM C876-09. (2009). Standard test method for corrosion potentials of uncoated reinforcing steel in concrete. PA: American Society for Testing and Materials.

ASTM D638-10. (2010). Standard test method for tensile properties of plastics. PA: American Society for Testing and Materials.

Bertolini, L. (2008). Steel corrosion and service life of reinforced concrete structures. Structure and Infrastructure Engineering, 4, 123-137. 
Bertolini, L., Bolzoni, F., Pastore, T., \& Pedeferri, P. (2004). Effectiveness of a conductive cementitious mortar anode for cathodic protection of steel in concrete. Cement and Concrete Research, 34, 681-694.

Bertolini, L., Bolzoni, F., Pedeferri, P., Lazzari, L., \& Pastore, T. (1998). Cathodic protection and cathodic prevention in concrete: principles and applications. Journal of Applied Electrochemistry, 28, 1321-1331.

Bertolini, L., Gastaldi, M., \& Pedeferri, M. P. (2007). Corrosion of reinforcement in concrete: Mechanisms, monitoring, inhibitors and rehabilitation techniques. European Federation of Corrosion Publications, 38, 62-74.

Bismarck, A., Kumru, M. E., Song, B., Springer, J., Moos, E., \& Karger-Kocsis, J. (1999a). Study on surface and mechanical fiber characteristics and their effect on the adhesion properties to a polycarbonate matrix tuned by anodic carbon fiber oxidation: Composites Part A. Applied Science and Manufacturing, 30, 1351-1366.

Bismarck, A., Kumru, M. E., Springer, J., \& Simitzis, J. (1999b). Surface properties of PAN-based carbon fibers tuned by anodic oxidation in different alkaline electrolyte systems. Applied Surface Science, 143, 45-55.

Brousseau, R., Arsenault, B., Dallaire, S., Rogers, D., Mumby, T., \& Dong, D. (1998). Sprayed titanium coatings for the cathodic protection of reinforced concrete. Journal of Thermal Spray Technology, 7 , 193-196.

BS EN 1504-4. (2004). Products and systems for the protection and repair of concrete structures Definitions, requirements, quality control and evaluation of conformity - Part 4: Structural bonding. London: British Standards Institute.

Bullard, S. J., Covino, B. S., Cramer, S. D., \& McGill, G. E. (1996). Thermal-sprayed zinc anodes for cathodic protection of steel reinforced concrete bridges. Proceedings of the 1st Global Internet Corrosion Conference.

Chung, D. D. L. (2000). Corrosion control of steel-reinforced concrete. Journal of Materials Engineering and Performance, 9, 585-588.

Cigna, R., Andrade, C., Nürnberger, U., Polder, R., Weydert, R., \& Seitz, E. (2003). Corrosion of steel in reinforced concrete structures, European cooperation in the field of scientific and technical research report, COST Action 521. Brussels: European Communities.

Cramer, S. D., Covino, B. S., Jr., Holcomb, G. R., Bullard, S. J., Collins, W. K., Govier, R. D., ... Laylor, H. M. (1999). Thermal sprayed titanium anode for cathodic protection of reinforced concrete bridges. Journal of Thermal Spray Technology, 8, 133-145.
Fukunaga, A., \& Ueda, S. (2000). Anodic surface oxidation for pitch-based carbon fibers and the interfacial bond strengths in epoxy matrices. Composites Science and Technology, 60, 249-254.

Gadve, S., Mukherjee, A., \& Malhotra, S. N. (2010a). Active protection of fiber-reinforced polymerwrapped reinforced concrete structures against corrosion. Corrosion, 67, 025002-1-025002-11.

Gadve, S., Mukherjee, A., \& Malhotra, S. N. (2010b). Corrosion protection of fiber-reinforced polymerwrapped reinforced concrete. ACl Materials Journal, 107, 349-356.

Gerardo, G. C., \& Donald, R. J. (1997). Performance of a conductive-paint anode in cathodic protection systems for inland concrete bridge piers in Virginia. Virginia: Virginia Transportation Research Council.

Gerardo, G. C., \& Donald, R. J. (2000). Cathodic protection of concrete bridge decks using titaniummesh anodes. Virginia: Virginia Transportation Research Council.

Li, L. Y., \& Page, C. L. (2000). Finite element modelling of chloride removal from concrete by an electrochemical method. Corrosion Science, 42, 2145-2165.

Orlikowski, J., Cebulski, S., \& Darowicki, K. (2004). Electrochemical investigations of conductive coatings applied as anodes in cathodic protection of reinforced concrete. Cement and Concrete Composites, 26, 721-728.

Pedeferri, P. (1996). Cathodic protection and cathodic prevention. Construction and Building Materials, 10, 391-402.

Takewaka, K. (1993). Cathodic protection for reinforced-concrete and prestressed-concrete structures. Corrosion Science, 35, 1617-1626.

Tang, L. (1999a). Concentration dependence of diffusion and migration of chloride ions: Part 1. Theoretical considerations. Cement and Concrete Research, 29, 1463-1468.

Tang, L. (1999b). Concentration dependence of diffusion and migration of chloride ions: Part 2. Experimental evaluations, Cement and Concrete Research, 29, 1469-1474.

Zhao, Y. X., Hu, B. Y., Yu, J., \& Jin, W. (2011). Nonuniform distribution of rust layer around steel bar in concrete. Corrosion Science, 53, 4300-4308.

Zhao,Y. X., Karimi, A. R., Wong, H. S., Hu, B., Buenfeld, N., \& Jin, W. (2011). Comparison of uniform and non-uniform corrosion induced damage in reinforced concrete based on a Gaussian description of the corrosion layer. Corrosion Science, 53, 2803-2814.

Zhu, J. H., Zhu, M. C., Han, N. X., Xing, F., \& Liu, W., (in press). Experimental investigation of CFRP plate used as an anode in simulated ICCP systems. Corrosion Science. 